\title{
CEMITÉRIO DE HOMENS VIVOS: SUPERLOTAÇÃO, DOENÇAS E MORTES NAS PRISÕES BRASILEIRAS ${ }^{1}$
}

\author{
Milton Júlio de Carvalho Filho
}

\section{INTRODUÇÃO}

Os desafios derivados da pandemia do COVID- $19^{2}$ para o sistema penitenciário brasileiro, não podem ser entendidos sem a articulação entre as categorias superpopulação prisional e condições de saúde/doença nas prisões. Essas categorias, dinamizadas analiticamente juntas, guardam correspondências e são propositivas de maior sentido, quando associadas à categoria raça. É sabido que a excessiva e muitas vezes arbitrária ${ }^{3}$ criminalização de homens negros ${ }^{4}$, principalmente pobres, por tráfico de drogas, acarreta o encarceramento, em regime fechado, em estabelecimentos prisionais superlotados, com condições ambientais desfavoráveis para manutenção da saúde. O entendimento de saúde, articulado com superpopulação prisional, considera condições crônicas de vida em prisões, como capazes de promover inscrições físicas e psíquicas nas pessoas aprisionadas, para além de manifestações de adoecimentos individuais, atribuindo a essas pessoas condição de supérfluas, extermináveis.

$\mathrm{O}$ crédito dado à superlotação prisional, como categoria central para pensar condições de saúde em prisões, advém da verificação do problema, pelo autor desse artigo, ao longo do tempo de realização de pesquisa de campo em prisões e pela literatura problematizadora da questão. A superlotação prisional não é apenas constituída pelo déficit de vagas; é um excedente populacional inadequado para as concretas condições ambientais das prisões; é uma afronta às leis, regulamentações e normas nacionais e internacionais; é demonstração de desrespeito à condição humana, principalmente em relação à manutenção da saúde física e psíquica. Parte expressiva da literatura, ao tratar da superlotação nas prisões de forma central ou transversal, compreende a relação entre o excesso de

${ }^{1}$ DOI 10.29388/978-65-86678-76-5-f.85-102

${ }^{2}$ Diversas matérias, produzidas por jornais, revistas e sites de produção e de divulgação de conteúdos, trataram da questão do COVID-19 no sistema penitenciário brasileiro. $\mathrm{Na}$ Internet são inúmeras as lives gravadas em canais do Youtube sobre o tema, muitas realizadas por acadêmicos, pesquisadores da questão prisional.

${ }^{3}$ Ver A verdade policial, como verdade jurídica. Narrativas do tráfico de drogas no sistema de justiça. Autoria de Maria Gorete Marques de Jesus. RBCS Vol. $35 \mathrm{n}^{\circ}$ 102/2020.

${ }^{4}$ Sobre a criminalização citada, ver: ANUNCIAÇÃO, D.; BONFIM, L. A.; FEIREIRA, T. "Mão na cabeça!": abordagem policial, racismo e violência estrutural entre jovens negros de três capitais do Nordeste. Saúde Soc., São Paulo, v. 29, n. 1, 2020. 
pessoas e a precarização da vida, tendo como consequência a promoção de adoecimentos físicos e psíquicos. Para as pessoas egressas das prisões, a superlotação demonstra que o sistema penitenciário não tem outro objetivo que não seja a promoção da violência física e simbólica, como medida corretiva. Para o escritor Luiz Alberto Mendes, após experiência de mais de vinte anos preso, as prisões no Brasil se constituem em "cemitérios de homens vivos ${ }^{5}$ ", corpos depositados e velados pelo Estado. A tutela estatal, por meio do sistema de justiça penal, não pode relativizar a vida, mas o faz, ao permitir a gestão inadequada de vidas aprisionadas e expô-las a riscos diversos, banalizando mortes nas prisões brasileiras.

Os riscos de contaminação do COVID-19 reacenderam à discussão sobre as péssimas condições de vida nas prisões brasileiras. Motivou a elaboração desse artigo o fato de essas mesmas condições produzirem inúmeros outros adoecimentos nas prisões, entre elas, doenças mentais e tuberculose. Os adoecimentos nas prisões, são geralmente tratados sem considerar singularidades da população aprisionada. Não se trata de adoecimentos em taxas comuns na sociedade, mas, pelo contrário, com índices superiores aos da população não aprisionada. São também adoecimentos de populações específicas, desconsideradas em seus processos de saúde. Entre as mais de oitocentas mil pessoas presas no Brasil em $2019,64 \%$ são negras e pobres. No estado da Bahia, onde estão cerca de 14.000 pessoas aprisionadas, mais de $90 \%$ delas são negras. Entretanto, a saúde da pessoa negra é pouco considerada nas estratégias de cuidados com a saúde para as pessoas aprisionadas.

A superlotação prisional não é considerada formalmente como causadora de danos para o processo de saúde das pessoas aprisionadas e assim amplia a vitimização e o extermínio de vidas. A superlotação é tratada, pelas autoridades, como um contexto, sem lastro histórico, sem demonstrações concretas dos danos gerados às vidas dessas pessoas e de suas famílias. As prisões brasileiras não estão superlotadas, elas são superlotadas. Faz parte da estratégia de punição do Estado brasileiro, promover o excedente da pena.

A Organização Mundial de Saúde - OMS declarou situação de pandemia em relação ao novo coronavírus, em março de 2020. Em janeiro do mesmo ano já havia emitido Declaração de Emergência em Saúde Pública de Importância Internacional. No Brasil, em fevereiro, o Ministério da Saúde emitiu a Declaração de Emergência em Saúde Pública de Importância Nacional e ainda em fevereiro, a Lei n. 13.979, dispôs sobre as medidas para enfrentamento do novo coronavírus. Em março, o Conselho Nacional

\footnotetext{
${ }^{5}$ Termo utilizado por Luiz Mendes em correspondência trocada como o autor desse artigo. Na época, em 2002, Mendes cumpria pena na Penitenciária do Estado de São Paulo.
} 
de Justiça, CNJ, emitiu a Recomendação 62 e, entre outras orientações, recomendava a soltura de pessoas presas, consideradas grupos de risco. Tal recomendação teve pouca aderência do judiciário. De certa forma, priorizou-se a lógica da segurança pública, em lugar das vidas aprisionadas, mesmo muitas delas consideradas grupos de risco para a Covid 19.

Com base nesse contexto de combate ao COVID-19 no sistema prisional, a pergunta de partida desse artigo foi assim sumarizada: como a superlotação prisional, rediscutida no Brasil a partir do advento do COVID-19, atua como fator de adoecimento nas prisões masculinas brasileiras, em regime fechado? Visamos contribuir para a ampliar a extensão da discussão sobre a superlotação prisional e associar a preocupação com a COVID-19 nas prisões brasileiras e especificamente baianas, com outros problemas crônicos das prisões, derivados também da superlotação, como a depressão e a tuberculose.

Realizamos seis entrevistas em profundidade, através de instrumento de coleta de dados semiestruturado. Entrevistamos três egressos do sistema prisional, dois diretores de unidades prisionais e um servidor(a) da área de saúde prisional do estado da Bahia. As entrevistas foram realizadas de maneira remota, através da elaboração de roteiros específicos e com campos comuns, visando demarcar quando a categoria superlotação era citada pelo entrevistado espontaneamente, relacionada a questão da saúde no sistema prisional. Também avaliamos como os entrevistados relacionavam superlotação prisional e saúde nas prisões, depois de provocados pelo entrevistador.

Os dados obtidos foram codificados para análise. As interpretações dos dados obtidos foram realizadas por meio de análise de conteúdo temático e em relação direta com a revisão de literatura. Finalmente, com base nos resultados do processo de análise temática dos conteúdos, passamos à escrita do texto. Iniciamos pelo advento do COVID-19, promotor da rediscussão sobre superlotação prisional no Brasil; após, estruturamos um breve relato histórico da superlotação para demonstrar que esse não é um problema de contextos específicos. Em seguida, analisamos os efeitos da superlotação para a saúde do homem aprisionado e nos centramos em alguns adoecimentos psíquicos e físicos, para finalmente retomarmos a discussão sumária sobre a COVID-19 nas prisões. Ao longo do texto, associamos os dados encontrados com a questão racial.

\section{A SUPERLOTAÇÃO PRISIONAL}

A superpopulação prisional não acarreta problemas de saúde das pessoas aprisionadas apenas em contexto de pandemia, mas é responsável por agravamentos de doenças crônicas, algumas anteriores ao aprisio- 
namento; outras adquiridas no cárcere e por muitas mortes silenciosas e estatisticamente imprecisas. A manutenção de homens em ambientes superlotados ao longo de anos, coaduna com o pensamento de Foucault (2004) sobre a face social e política da pena e como extrapola a punição criminal. A economia do castigo é uma economia política e é endereçada a determinados grupos sociais.

É impreciso o quantitativo de mortes nas prisões. Tal imprecisão se deve às mortes nas prisões estarem relacionadas a um padrão de gestão estatal, a gestão de precárias ambiências prisionais. Outro fato que gera a imprecisão do número de mortos é a falta de acompanhamento de egressos e de pessoas aprisionadas com doenças pré-existentes. Além disso, mortes em prisões, assumem caráter de normalidade, ainda que sejam persistentes violações de direitos das pessoas aprisionadas, especialmente em relação ao direito à vida (BOGO; ROTTA, 2019, p. 86). Ainda que destruam subjetividades e matem, as prisões brasileiras seguem blindadas, sem prestar contas das vidas desperdiçadas: sujeitos negros e pobres, segregados em nome da lei e da ordem pública. Essa blindagem, de certa maneira, é o que Flauzina (2006, p. 124) considera "[...] a blindagem erguida em torno do institucional, como forma de preservar a inscrição do racismo em suas práticas [...]."

A superlotação prisional é um desrespeito à Declaração Universal dos Direitos Humanos principalmente em relação ao "Artigo III - Todo ser humano tem direito à vida, à liberdade e à segurança pessoal." e ao "Artigo V - Ninguém será submetido à tortura, nem a tratamento ou castigo cruel, desumano ou degradante.". Também desrespeita às Normas e Princípios das Nações Unidas sobre Prevenção ao Crime e Justiça Criminal (2009), capítulo 1 que trata sobre Regras mínimas, padrões para o tratamento de prisioneiros entre outras, às seguintes:

Princípio básico:

6. (1) As regras a seguir devem ser aplicadas imparcialmente. Não deve haver discriminação quanto à raça, cor, sexo, idioma, religião, opinião política ou outra, origem nacional ou social, propriedades, nascimento ou outras situações. (pág. 13)

Acomodação:

9. (1) As celas ou quartos destinados ao descanso noturno, não devem ser ocupados por mais de um prisioneiro. Se, por razões especiais, tais como superlotação temporária, for necessário que a administração central penitenciária faça uma exceção à regra, não é recomendável que dois prisioneiros sejam alojados em uma mesma cela ou quarto. (pag.14) 
10. Todas as acomodações para uso dos prisioneiros e, em particular, todos os dormitórios devem satisfazer as exigências de higiene e saúde. Deve-se dar a devida consideração às condições climáticas e, particularmente, ao espaço mínimo, iluminação, aquecimento e ventilação. (pág. 15)

Serviços médicos

22. (1) Toda instituição deve oferecer os serviços de pelo menos um médico qualificado com alguns conhecimentos de psiquiatria. Os serviços médicos devem ser organizados em conjunto com a administração geral de saúde da comunidade ou da nação. Devem-se incluir um serviço psiquiátrico para diagnósticos e, em casos apropriados, para tratamento de estados de perturbação mental. (2) Prisioneiros doentes que necessitarem tratamento especializado devem ser transferidos para instituições especializadas ou hospitais civis. (pag. 16)

A superlotação nas prisões brasileiras atenta também contra a Lei de Execução Penal Brasileira - LEP, artigo 85 - quando considera a lotação das prisões em compatibilidade com sua estrutura e finalidade. A LEP também indica que é de competência do Conselho Nacional de Política Criminal e Penitenciária determinar o limite máximo de capacidade do estabelecimento. Mais do que um problema de gestão prisional, a superlotação corresponde à violação sistemática de direitos, voltada a alguns grupos sociais considerados "corpos torturáveis" (BICALHO; RANGEL, 2016, p. 422). Assim, as prisões descumprem também a Constituição brasileira de 1988, no estabelecimento de garantia do Estado na promoção do bem-estar de todos, sem preconceitos e discriminações e quando assegura a inadmissibilidade da tortura e de tratamentos desumanos ou degradantes. As legislações têm limites de êxito no que tange ao sistema prisional brasileiro quando este mantém estruturas e serviços prisionais inadequadas, frente aos marcos legais e atribui prejuízos diretos para as pessoas aprisionadas e seus familiares.

A literatura sobre superlotação prisional a explica de diversas maneiras: uma delas é como consequência de um modelo de justiça reforçador da pena de privação de liberdade como resposta mais forte para a prática de delitos, em detrimento de um modelo de justiça voltado a reconstituir a estrutura social afligida pelo delito (BERTOLLA e LUSA, 2018). Há também entendimentos sobre as relações entre superlotação e reincidência criminal e a superlotação como desqualificadora de propostas de ressocialização, quando existente ${ }^{6}$. (COSTA; MOREIRA, 2019). A literatura também indica correlações entre superlotação e políticas de encar-

${ }^{6}$ Adendo do autor. 
ceramento em massa. Relacionada à perspectiva anteriormente citada, DANTAS (2012) associa a superlotação ao genocídio de jovens negros, resultante do combate ao tráfico de drogas e ao fácil acesso às armas de fogo. Autores também indicam como a superlotação resulta em consequências para a gestão prisional, principalmente em relação à imposição de negociações dos gestores prisionais com grupos organizados dentro das prisões, visando a manutenção da ordem interna. A superlotação também atinge os familiares de presos, ou seja, tem efeitos externos à prisão. (SINHORETTO; SILVESTRE; MELO, 2013). Mas, o que resolve o déficit de vagas? FISCHER e ADORNO $(1987$, p. 79$)$ ao discutirem o fracasso do sistema penitenciário brasileiro perguntam: "Será eficaz persistir na política de aumento do número de vagas?" A questão prisional é política com necessidade urgente de debate e reformulação, devido à comprovação de as prisões no Brasil, punirem mal, serem inseguras e amontoarem indivíduos em condições precárias, desumanas (ROCHA, 2006)

\section{A SUPERLOTAÇÃO DAS PRISÕES NO BRASIL: UMA HISTÓRIA DE DESRESPEITOS:}

A memória das instituições prisionais no Brasil, presente na literatura histórica, sociológica ou antropológica, demonstra que a superlotação e as precárias condições dos presídios, são condições comuns em variadas épocas. Trabalhos como os de Di Santis e Engbruch (2012), Salla (1999) e Souza (2009) auxiliaram, cada um ao seu modo, nesse percurso histórico e demonstraram que, mesmo com tentativas de modernização das prisões brasileiras com base na valorização de modelos prisionais estrangeiros e reformas legais, as prisões brasileiras logo viviam ajustes e sucateamentos.

No Rio de Janeiro, em 1808, a prisão do Aljube, destinada a pessoas escravizadas e livres, viveu a superlotação e o governo tentou resolver o problema transferindo as pessoas presas para navios ancorados e para antigos fortes e fortalezas, adaptados para servirem de prisões. Esta iniciativa oitocentista no Rio de Janeiro se associa com algumas, atuais, 
quando, em 2016, em $2018^{8}$ e em $2020^{9}$, autoridades brasileiras pensaram, sem implementação, em resolver a superlotação e o afastamento de presos com sintomas de COVID-19, transferindo-os para contêineres.

Em 1824, a constituição do império já atentava para a questão prisional ao mencionar que as prisões deveriam ser claras e bem arejadas. Quatro anos mais tarde, estabeleceu-se comissões de cidadãos para visitar e fiscalizar às condições das prisões. Ao longo de alguns anos, contradizendo as indicações constitucionais, a comissão constatou: falta de espaço; mistura de presos condenados e provisórios, falta de condições de higiene, insalubridade, falta de assistência médica e alimentação precárias, falta de água, acúmulo de lixo (DI SANTIS; ENGBRUCH, 2012). Esses problemas persistem em muitas prisões brasileiras na atualidade. Ainda com base em Di Santis e Engbruch (2012), em 1841 outro relatório da comissão considerava a prisão como escola de imoralidade, mantida pelas autoridades e financiada por recursos públicos e propunha a separação das pessoas presas, portadoras de doenças psíquicas, além de considerar a necessária melhoria nas condições ambientais e alimentares nos presídios.

O Primeiro Código Penal da República Brasileira, em 1890, estabeleceu tipologias prisionais como a prisão Celular para crimes comuns; as prisões em fortalezas ou locais militares para crimes políticos; as prisões agrícolas e de trabalho. Nessa época, já havia déficit de vagas nas prisões celulares. Em 1906, 976 presos condenados no estado de São Paulo concorriam as 160 vagas existentes em prisões celulares, e essas já viviam a deterioração do ambiente. (ANDRADE et al., 1990)

Considerações sobre aberturas de vagas em prisões como melhor resolução para a superlotação é também antiga no Brasil. No país, nunca se pensou, governamentalmente, em parar de prender. Em 1920, foi inaugurada a Casa de Detenção de São Paulo, estabelecimento com 1.200 vagas, grande número para a época. Esta unidade prisional foi considerada diferenciada das demais do país, mas ao longo de vinte anos viu sua estrutura ser sucateada por conta da superlotação e vinte anos depois

\footnotetext{
7 Vide Governo do RS confirma que vai usar contêineres como celas provisórias. Disponível em: http://g1.globo.com/rs/rio-grande-do-sul/noticia/2016/11/governodo-rs-confirma-que-vai-usar-conteineres-como-celas-provisorias.html Acesso em:23 mar. 2021.

${ }^{8}$ Vide. Paraná recorre a vergonhosos contêineres para abrigar presos. Disponível em: http://www.justificando.com/2018/02/05/parana-recorre-vergonhosos-conteinerespara-abrigar-presos/. Acesso em: 23 mar. 2021.

${ }^{9}$ Vide Covid-19: Depen sugere contêineres para separar presos com sintomas. Uso de estrutura modular temporária precisa da autorização do CNPCP. . Disponível em: https://agenciabrasil.ebc.com.br/geral/noticia/2020-04/covid-19-depen-sugere-conteineres-para-separar-presos-com-sintomas. Acesso em:23 mar. 2021.
} 
acumulava a terrível estatística de $12 \%$ de presos mortos por tuberculose (DI SANTIS; ENGBRUCH, 2012) A quantidade de vagas dessa unidade prisional foi ampliada em 1959, para 3.000 pessoas, mas abrigou cerca de oito mil. Em 1992, essa mesma prisão foi manchete da mídia nacional, quando, no mínimo, cento e onze homens presos foram mortos no denominado "Massacre do Carandiru", uma ação violenta da polícia militar paulista, quando acionada para conter uma rebelião. O massacre não produziu responsabilizações para o Estado, depois de processos judiciais longos e imprecisos.

Entre 1995 e 1997, o déficit de vagas cresceu no Brasil e atingiu 27\%. Em 2001, as prisões brasileiras, especialmente em São Paulo, foram sacudidas por outra ocorrência, nova até aquele momento, as rebeliões simultâneas, ocorridas em vinte e nove unidades prisionais do Estado, com pauta, entre outras, sobre as más condições das prisões, embora não tenha sido essa a principal (SALLA, 2006). Em 2008, a Comissão Parlamentar de Inquérito do sistema Carcerário, divulgou relatório cujo foco era a superlotação no sistema prisional. A comissão encontra $89 \%$ da população prisional em unidades com déficit de vagas, independente do regime de cumprimento da pena. O relator, deputado Sérgio Brito, desabafou em seu texto, constante do Relatório Final da Comissão Parlamentar de Inquérito Destinada a Investigar a Realidade do Sistema Carcerário Brasileiro (2015):

O Sistema Carcerário Brasileiro, como se sabe, há algum tempo encontra-se em situação preocupante e que demanda especial atenção do Estado. Não é por outra razão, inclusive, que esta é a segunda Comissão Parlamentar de Inquérito criada no âmbito desta Casa Legislativa, em um interregno inferior a 08 (oito) anos, com a finalidade de investigar a realidade desse sistema. (pag.8)

E complementou:

[...] Afinal, de nada adianta constatar que não se respeitam os direitos dos presos, que há superlotação dos presídios, que há déficit de servidores, que as organizações criminosas exercem domínio nos presídios, e não autuar no sentido de propor soluções para enfrentar essa realidade. (pag. 16)

Em 2011, o Brasil teve outro grande incremento quantitativo do encarceramento penal, superando meio milhão de presos. Cinco anos depois, em 2016, a população prisional alcançou o número de 726.712 pessoas $^{10}$. Nesse mesmo ano, eram 368.049 vagas no sistema e o déficit era

\footnotetext{
${ }^{10}$ Vide Há 726.712 pessoas presas no Brasil. Disponível em: https://www.justica.gov.
} br/news/ha-726-712-pessoas-presas-no-brasil. Acesso em:23 mar. 2021 . 
de 358.663. a taxa de ocupação dos presídios chegou a 197,4\% e taxa de aprisionamento de 352,6 para cem mil habitantes. Em 2020, o número de pessoas presas passou de 800.000 , fazendo o país alcançar o terceiro lugar no ranking de aprisionamento no mundo, abaixo apenas dos EUA e da China. Ao longo de todos esses anos, manteve-se expressivo o percentual de homens negros aprisionados, entre 58 e $64 \%$.

A superlotação é também seletiva e desafiadora. Na pesquisa realizada com gestores de prisões na Bahia, a superlotação aparece espontaneamente quando perguntados sobre os principais desafios que enfrentam na gestão. Para um entrevistado:

A primeira pontuação que eu quero fazer, sobre uma dificuldade que sinto é: em qualquer local, em qualquer unidade prisional brasileira, eu ainda não vi, eu não recebi nenhuma informação de uma unidade no Brasil que não tivesse o excesso populacional. 0 excesso populacional é uma das grandes dificuldades de qualquer gestor prisional. Digo isso porque em qualquer projeto, a logística é alterada em função da população a ser atendida. (...) No sistema prisional é a mesma coisa: a lotação das prisões extrapola em muito. Então, toda logística de alimentação, de segurança e de saúde, é alterada. (GESTOR PRISIONAL, 2020)

O mesmo gestor indica a superlotação da unidade prisional gerida por ele na Bahia. A unidade atende a pessoas condenadas e pessoas aguardando julgamento: "A unidade tem capacidade para 600 internos, mas, chegamos a 1.450. Com a pandemia, foi a primeira vez que baixamos da casa de mil condenados e provisórios." (GESTOR PRISIONAL, 2020) A superlotação afeta a gestão e tenciona as relações entre os aprisionados. Tudo isso, compõe um conjunto de fatores de adoecimentos, como as doenças psíquicas.

\section{O MASCULINO NOCIVO E O MEIO AMBIENTE ADOECIDO DAS PRISÕES:}

Com o advento da COVID-19, uma das estratégias utilizadas para evitar a propagação do vírus nas prisões foi a suspensão das visitas. Essa estratégia não é fácil para nenhum dos lados em jogo: para a gestão prisional, implica em conter os ânimos das pessoas encarceradas, para evitar crises; para as pessoas aprisionadas significa maior afastamento familiar; falta de encontros sexuais; falta de abastecimentos levado pelas famílias; perda de contato, direto, com pessoas do mundo exterior. Assim, sobram tensões, já existentes, mas acirradas, entre a gestão e as pessoas aprisionadas; entre os próprios aprisionados. (ANDRADE et al., 1990). As prisões masculinas são instituições homoparticipativas; com baixa circulação de 
afetos; povoadas e geridas por homens, sejam eles da direção, policiais penais e aprisionados; majoritariamente identificados como heterossexuais, detentores de uma masculinidade clássica, tradicional, reforçadora de conteúdos valorizadores de virilidade; de subjugação do outro; de demonstrações de poder e de habilidades para agir violentamente; de vingança; de valorização de uma moral masculina. Esses homens pensam o masculino a partir dos privilégios atribuídos a essa condição, entre esses a capacidade de administração da dor e do medo. É comum não assumirem fragilidades físicas ou psicológicas e adoecimentos, exceto quando agravados, como salientam os egressos entrevistados: "Eu sofria, mas não me queixava, isso era para os fracos"; "Quando apanhei lá, enrijeci os músculos e não senti foi nada!"; "Minha cabeça ficou fraca lá, mas eu tentava despovoar minha mente de tanta pressão, ai não me dei de mal". O não adoecer, saber sentir dor e não demonstrar fraquezas está associado a constituição de um tipo de masculinidade valorizada entre muitos homens e alimentada por um imaginário de força e de potência, inclusive em relação às adversidades de vida, como a superlotação e a precariedade ambiental as quais estão submetidos. Sobreviver a essas condições é mérito masculino para alguns. Nesse sentido, um dos egressos do sistema penitenciário, entrevistado, considerou: "Quem vive nas condições de lá, só tem duas chances: $70 \%$ de sair morto e $30 \%$ de sair acabado, mas vivo". Para outro egresso entrevistado "Tem que ser bicho homem pra segurar: vivi com mais 17, espaço pequeno, gente doente, gente doida, calor". Outro relata como se sentia e agia: "Eu vestia uma camisa de força em mim, o que sentia, guardava aqui dentro (aponta o coração)".

A demonstração da emoção é um capital altamente desvalorizado nas prisões masculinas, e em seu lugar, um acervo de códigos, de regras de conduta ameaçadoras, regulam as relações e promovem o silenciamento sobre mortes, maus tratos, torturas e adoecimentos. A vivência nessas condições de convivência, em prisões superlotadas, justifica os resultados do estudo realizado por Freire, Pondé e Mendonça (2012) que indica a prevalência de doenças mentais entre pessoas aprisionadas em Salvador, Bahia, indistintamente se em regime fechado ou semiaberto, como sendo entre 5 e 10 vezes maior do que na população em geral, principalmente depressão, transtornos de ansiedade e do sono. Em outra pesquisa, também em Salvador, Coelho (2012) identificou: a falta de profissionais especializados para o atendimento de saúde mental na prisão estudada; o agravamento de problemas de saúde mental, devido à demora da assistência; a falta de diagnósticos médicos quando da entrada na prisão. A autora aponta $90 \%$ dos pesquisados, sem tratamento psiquiátrico ou psicológico ao longo de toda a sua vida e sugere uma associação direta entre presença de transtornos mentais no ambiente prisional e a super- 
população carcerária. Sobre isso diz um dos egressos entrevistados: "Vi gente pirar, não suportar viver como bicho."; outro egresso complementa em sua entrevista: "Às vezes ser atendido lá pelo psiquiatra era pior. Eles davam remédios que deixavam a pessoa lerda, lenta, vacilando". Além de problemas de saúde mental, os gestores prisionais entrevistados identificam a superlotação como causadora de outros problemas de saúde.

Eu percebo grandes demandas na saúde que afligem, muito, o sistema carcerário: o tabagismo ${ }^{11}$ e a tuberculose. Outros problemas também, são os ordem mental. $\mathrm{O}$ cárcere promove um distanciamento da família e, mesmo que sejam feitos todos os esforços para que a família esteja com o apenado, o distanciamento do centro familiar traz diversos complicadores, agravantes na saúde mental do interno. Então, o tabagismo, a tubérculos e a saúde mental, são os principais problemas relativos à saúde, verificados no sistema prisional. (GESTOR PRISIONAL, 2020)

\section{A SUPERLOTAÇÃO E A TUBERCULOSE NAS PRISÕES BRASILEIRAS}

É comum ao homem brasileiro, ainda que não seja esse um grupo homogêneo, um comportamento relapso em relação aos cuidados com a saúde. Essa constatação pode explicar a maior prevalência de diabetes, hipertensão arterial, doenças sexualmente transmissíveis, doenças cardiovasculares e acidentes vasculares cerebrais, entre os homens, além de tempo de vida menor do que o das mulheres. No tocante aos homens negros, o quadro de saúde é ainda mais frágil e exige ampliação de estudos específicos, considerando, a caracterização comum desse grupo, mencionada por Batista (2005, p.71-79): "[...] baixa escolaridade; residência em áreas periféricas, pobres, sem infraestrutura; poucos acessos à direitos sociais; salário médio mensal baixo, menor que homens brancos". Assim, Batista (2005) afirma a saúde e a doença como construções sociais, diretamente influenciados pela demarcação dos espaços de gênero e de raça, ocupados em uma sociedade. Nesse sentido, entende-se os motivos pelos quais a tuberculose no Brasil, atinge mais homens negros, $16,13 \%$ do que brancos, 4,88\%, com letalidade também maior entre os homens negros. Isso pode ser explicado pelo fato de homens negros e brancos ocuparem espaços diversos na sociedade brasileira, o que acarreta na desproporcionalidade entre eles, também no espaço prisional. Para Batista devemos analisar prevalência de doenças e mortes em perspectiva relacional, para ampliar a discussão sobre a relação entre construção social e o processo

\footnotetext{
11 Não encontramos expressivo número de estudos, específicos, sobre prevalência de tabagismo na população prisional brasileira. Consideramos ser esse um tema de pesquisa necessário.
} 
de saúde, doença e morte. O autor ressalta a vulnerabilidade social e programática das pessoas negras no Brasil como explicativas das suas vitimizações em saúde e como fatos políticos que comunicam desigualdades raciais em saúde. (BATISTA, 2005)

Nas prisões, todo esse quadro social de adoecimento de homens negros se agrava, inclusive com mortes por doenças tratáveis. A superlotação amplia a dificuldade do atendimento de saúde e isso faz com que seja seis vezes maior a chance de morrer na prisão, do que fora dela. As mortes por motivo de doenças, nas prisões, correspondem a $80 \%$ do total de mortes, enquanto mortes por motivos de violências diversas, correspondem a 10\%. (VALENÇA, 2016). A cada 10.000 presos, 900 tem tuberculose e muitos morrem em virtude de uma doença tratável.

A tuberculose é uma doença infectocontagiosa, transmitida por via aérea, e acomete o pulmão em $90 \%$ dos casos. Do ponto de vista da transmissibilidade, tem potencial mais forte que a AIDS (MENEZES, 2002). A superlotação amplifica a disseminação do bacilo, seja pelo fluxo de entradas no sistema prisional, de pessoas já doentes, seja pelos adoecidos na prisão, tornando a tuberculose a doença mais frequente e grave do sistema prisional e, desse modo, um grave problema de saúde pública. As entradas diárias de pessoas aprisionadas, sem diagnóstico médico, as transferências entre unidades prisionais e as saídas de pessoas da prisão, principalmente de pessoas aprisionadas provisoriamente, faz com a disseminação se dê, para dentro e para fora da prisão. (LAROUZÉ et al., 2015) As solturas e as transferências de pessoas aprisionadas também promovem interrupções no tratamento da doença, sem o acompanhamento devido. Além desses aspectos anteriormente mencionados, a demora no diagnóstico, a falta de exames radiológicos e laboratoriais, fazem com que a tuberculose seja considerada outra pena, associada a pena de prisão. (LAROUZÉ et al., 2015) Um dos egressos entrevistados conta:

Enquanto estava preso tive coisa que nunca tinha tido antes: tive sarna, sudorese, piolho, uma tosse desgraçada que depois fiquei sabendo que era tuberculose. Estava numa cela úmida, com mais 17 e sabia que, mais cedo ou mais tarde, eu iria pegar. Tinha outros lá doentes e os caras falavam: "tosse pra lá!" Pedia médico e me diziam: "pra que?" Até que fui, e descobri. Perdi peso, fiquei mal, mas o que mais me doeu foi ter passado isso pra minha mulher e meu filho, sem saber. (EGRESSO, 2019)

Nas prisões em Salvador, Bahia, o Programa de Controle da Tuberculose nas instituições penais foi estudado por Menezes (2002) e identificado à superlotação como a principal causa de disseminação da doença. A autora localizou também uma crescente associação entre tuberculose e 
HIV e indicou a inexistência de busca ativa de sintomáticos respiratórios, entre as pessoas aprisionadas na Bahia, o que ocasionava deficiência na detecção de doentes bacilíferos. Já no Rio de Janeiro, Sánchez e Larouzé (2016) após realizarem estudo sobre tuberculose nas prisões, advertem aos gestores públicos quanto a urgência em assumirem suas responsabilidades em relação a saúde das pessoas aprisionadas. Também no Rio de Janeiro, Minayo e Ribeiro (2015), identificaram relação direta entre problemas de saúde na prisão e superlotação. Na prisão estudada pelas autoras, mais de $70 \%$ dos homens aprisionados eram negros. Entre os problemas de saúde física desses homens, as autoras encontraram: dores no pescoço, costas e coluna; luxação de articulação, bursite, dor ciática, artrite, fratura óssea, problemas de ossos e cartilagens e de músculos e tendões, sinusite, rinite alérgica, bronquite crônica, tuberculose e doenças de pele. Com o advento do COVID-19, a responsabilidade das autoridades públicas quanto a saúde prisional, cresce. O COVID-19 é mais um elemento que nos faz pensar sobre os cuidados com a saúde das pessoas aprisionadas, não como um privilégio, desmerecido, mas como um direito que tem sido negado.

\section{A SUPERLOTAÇÃO E A COVID NAS PRISÕES BRASILEIRAS}

Ainda que sem comparações diretas sobre diferentes contextos e distintas doenças, lembramos que quando ocorreu a gripe espanhola no Brasil, em 1918, o número de casos entre as pessoas aprisionadas em prisões da cidade de Salvador, chegou a $82 \%$, segundo Souza (2009). A autora mostra que esse elevado percentual de contaminação se deu em função do contato das pessoas aprisionadas com outras vindas do ambiente externo. A preocupação com o fluxo de entradas e saídas das prisões, principalmente de novas pessoas aprisionadas, de funcionários e de fornecedores diversos, também é aspecto preocupante nas estratégias de combate à disseminação do COVID-19 nas prisões. Não é possível promover isolamento em prisões superlotadas e com grande fluxo de pessoas entrando e saindo. Ainda que os dados relativos à saúde no sistema prisional sejam, de certa maneira, ainda frágeis, para acompanhar a dinâmica de doenças no curto prazo, um gestor prisional entrevistado relata a contaminação por COVID-19 entre policiais penais e demonstra como circulam os números:

O nosso quadro de saúde (adoecimento) é proporcional à situação da cidade. Saiu na imprensa que estaríamos com 40 positivados por COVID, mas isso não verdade. A imprensa quando informou isso nós não tínhamos nem 20 funcionários positivados. Depois, esse número aumentou e chegou ao pico de 70 e agora estamos 
tendo o retorno desses colaboradores. (GESTOR PRISIONAL, 2020)

Além dos policiais penais, as famílias das pessoas aprisionadas foram também consideradas como potenciais transmissoras do vírus, o que foi usado como justificativa para a suspensão das visitas e a manutenção do isolamento social. Sobre a suspensão das visitas, um gestor prisional entrevistado adverte: "A falta de visita é uma situação delicada. Após a pandemia, a psicologia e a psiquiatria terão demandas maiores do sistema. Teremos aumento de problemas de ordem mental." (GESTOR PRISIONAL, 2020). Na Bahia, um plano de crise para o combate do COVID-19 no sistema penitenciário do Estado foi criado pela Secretaria de Administração Penitenciária, mas com a manutenção de problemas estruturais e históricos, com os quais se naturaliza a operação do sistema prisional, dificilmente se evitará a disseminação dessa doença, assim como de outras doenças infectocontagiosas que podem vir em fluxo. Sánchez et al (2020) alerta, considerando a superlotação das prisões, uma necessária vigilância na detecção da entrada do vírus nas prisões, para que haja um célere bloqueio, visando evitar à disseminação massiva. A vulnerabilidade da população carcerária faz parte da dinâmica do sistema e precisa ser repensada. Também e tal qual na época da gripe espanhola, a superlotação de pessoas aprisionadas em pequenos espaços, com ventilação e iluminação precários, em condições insalubres e com alimentação de qualidade duvidosa, são fatores potenciais para o agravamento da disseminação da COVID, nas prisões brasileiras. Para Sánchez et al (2020), sobre a COVID:

Na população livre estima-se que cada infectado contamine 2 a 3 pessoas. Dadas as condições de encarceramento nas prisões brasileiras, pode-se estimar que um caso contamine até 10 pessoas. (pag.1)

Ressalta Sánchez (2020) que a pandemia chegou ao Brasil e encontrou um sistema prisional frágil e sobrecarregado. Salientamos que tal situação é histórica. Para a autora isso impossibilita comparações entre os efeitos da doença nas prisões brasileiras com as prisões da Europa central, pois nessas prisões a disseminação do vírus não foi expressiva, em virtude das celas, mesmo quando coletivas, não abrigarem mais de quatro presos e condições ambientais melhores do que as das prisões brasileiras, ou seja não há, entre essas prisões europeias, parâmetros de comparação com a superlotação vivida no Brasil. Em pesquisa comparativa sobre as condições de aprisionamento no Brasil e em outros países, como França, Portugal, entre outros, CARVALHO FILHO (2019), adverte:

Para entender o colapso dos sistemas prisionais mundiais, divulgado amplamente em mídias distintas, de países diversos, é neces- 
sário conhecer o aumento da quantidade de pessoas aprisionadas no mundo. Quanto mais se aprisionam pessoas, mais as causas promotoras do colapso do sistema são ampliadas, como a superlotação prisional e as precárias condições de vida e de assistência social e de saúde nas prisões que acarretam danos à saúde física e psíquica das pessoas aprisionadas. Em tais condições, o crescimento da população prisional no mundo é preocupante. (pag. 200)

O encarceramento em massa, como política de combate às drogas e o aprisionamento em regime fechado como prioridade punitiva do sistema de justiça, carecem de revisão no Brasil. O colapso do sistema de saúde nas prisões superlotadas é mais um entre outros colapsos do sistema prisional: alimentação ruim; instalações precárias e insalubres; processos de educação das pessoas aprisionadas pouco considerado nas suas singularidades; insegurança e violência são outras consequências da superlotação em um sistema dirigido a uma parcela expressiva da população brasileira, ajustado à criminalização da pobreza, das drogas e prioritariamente, das pessoas negras. As prisões brasileiras associam sacrifício, terror e humilhação, são na expressão de Mbembe (2016, p.25): “"'mundos de morte"'”, e como tal são locais onde "[...] vastas populações são submetidas a condições de vida que lhes conferem o status de "mortos-vivos" (pag.25).

\section{CONSIDERAÇÕES FINAIS}

No Brasil, o sistema prisional tem forte herança colonial e escravista. A superlotação nas prisões se mantém, também devido à sociedade brasileira, de modo geral, se mostrar desinteressada em relação aos problemas do sistema prisional e de certa maneira, considerar "quanto pior, melhor a prisão", convencida da necessidade de punição, para além da pena de privação de liberdade. Dessa maneira, a sociedade goza, com a sensação de vingança que excede a pena. A superlotação faz parte do imaginário vingativo do brasileiro. Isso em virtude de as prisões no Brasil voltarem-se para os mais pobres e para os negros. A história da superlotação das prisões no Brasil mostra que o arranjo prisional, precário e adoecedor, tem, desde sempre, público alvo. As pessoas aprisionadas, em sua maioria, homens negros, desconsiderados pela matriz econômica da sociedade brasileira, muitas vezes, até mesmo, como força de trabalho barata, são colocados em condição sub-humanas de vida. São esses homens que sucumbem nas prisões, depois de viverem o autoritarismo e os abusos das forças policiais do Estado; de se subordinarem a parcela do tráfico de drogas que tiranicamente ocupa as áreas periféricas onde eles residem; de viverem a lentidão, a incompreensão e diversas condenações sociais, morais e econômicas da justiça. Nas prisões superlotadas, em re- 
gime fechado, muitos deles adoecem e morrem.

Na prisão brasileira, a superlotação é a câmara de gás que mata aos poucos e promove uma morte dissimulada por "causas naturais", em estatísticas pouco claras. Afinal, os homens tinham depressão e por isso se suicidaram; afinal tiveram uma "gripezinha ${ }^{12 ", ~ u m a ~ t u b e r c u l o s e ~ e ~ p o r ~}$ isso morreram. Mas, as prisões brasileiras são também diferentes dos campos de concentração; são mais do que instituições totais; visam mais do que vigiar e punir. As prisões são instituições sintetizadoras de um potente e quase sempre negado imaginário brasileiro: segregacionista, higienizador e seletivo. Nesse sentido, é também uma instituição ambígua e se estrutura nas suas contradições: anuncia transformar vidas em nome da justiça e da ordem, mas é uma máquina arbitrária, precária e arcaica; anuncia desejar ressocializar, mas nega a mínima condição cidadã aos sujeitos aprisionados; anuncia fazer justiça, quando é, fundamentalmente vingança; anuncia cuidar, tutelar, quando na verdade faz adoecer e mata.

\section{REFERÊNCIAS}

ANDRADE, C. C. et al. $O$ desafio da reintegração social do preso: uma pesquisa em estabelecimentos prisionais. Rio de Janeiro: Ipea, 1990.

BATISTA, L.E. Masculinidade, raça/cor e saúde. Ciência \& Saúde Coletiva, Rio de Janeiro, v.10, n.1, 2005, pp.71-80.

BERTOLLA, L. M. A.; LUSA, E. Repensando a Justiça Retributiva e sua superpopulação carcerária: a saída está na justiça restaurativa? Ciências Sociais Aplicadas em Revista, v.18 - n. 34 - 10 sem.2018 - pp. 133 a 143

BICALHO, P. P. G.; RANGEL, F. M. Superlotação das prisões brasileiras: Operador político da racionalidade contemporânea. Estudos de Psicologia, , v. 21, n. 4, 2016.

BOGO, C. L. A.; ROTTA, A. B. Mortes sob custódia prisional no Brasil. Prisões que matam; mortes que pouco importam. Rev. Ciências. Sociais, DS-FCS, v. 32, n.o 45, julho-dezembro 2019. pp. 67-90.

BRASIL. Constituição (1988). Constituição da República Federativa do Brasil de 1988. Brasília, DF: Presidência da República, 2016.

BRASIL. Política Nacional de Atenção Integral à Saúde das Pessoas Privadas de Liberdade no Sistema Prisional/ Ministério da Saúde, Secretaria de Atenção à Saúde, Departamento de Ações Programáticas Estratégicas, Coordenação de Saúde no Sistema Prisional - 1. Ed - Brasília: Ministério da Saúde, 2014. 60 p.

BRASIL. Ministério da Justiça. Secretaria Nacional de Justiça. Normas e

${ }^{12}$ Expressão usada pelo Presidente do Brasil, em 2020, para tratar da COVID. 
princípios das Nações Unidas sobre prevenção ao crime e justiça criminal /Organização: Secretaria Nacional de Justiça. - Brasília: Secretaria Nacional de Justiça, 2009. 344 p.

BRASIL. Câmara dos Deputados- CPI - Sistema Carcerário Brasileiro - Relatório Final da Comissão Parlamentar de Inquérito destinada a Investigar a Realidade do Sistema Carcerário Brasileiro Presidente: Deputado Alberto Fraga Relator: Deputado Sérgio Brito Brasília, agosto de 2015, $437 p$.

CARVALHO, F.; MILTON, J. Condições de aprisionamento judicial em regime fechado: panorama de um colapso em escala mundial. In: ROCHA, J. C. S. da et al (orgs). Segurança Pública: direitos humanos e sistema de justiça. Salvador: Edufba, 2019, p 187-208.

COELHO, M. T. A. D. A saúde mental de infratores presos numa unidade prisional da cidade do Salvador. In: Maria Thereza, Dantas Ávila Coelho e Milton Júlio de Carvalho Filho (Orgs) Prisões numa abordagem interdisciplinar. Salvador: EDUFBA, 2012, p 131-144.

COSTA, J. C. R.; MOREIRA, M. O sistema prisional: superlotação e ressocialização. Revista Vox, n. 10, jul.-dez. 2019. p. 22-33.

DANTAS, A. L. T. Superpopulação carcerária no Rio de Janeiro regulada pela economia da droga: um efeito da política de criminalização imposta aos jovens residentes das comunidades carentes. 2012. 230. Tese (Doutorado em Políticas Públicas) - Programa de Pós-Graduação em Política Pública e Formação Humana, Universidade do Estado do Rio de Janeiro, Rio de Janeiro, 2012.

DI SANTIS, B. M.; ENGBRUCH, W. A evolução histórica do sistema prisional e a Penitenciária do Estado de São Paulo. Revista Liberdades, n. 11, setembro-dezembro, 2012. p 143-160.

FISCHER, R. M.; ADORNO, S. Políticas penitenciárias, um fracasso? Lua Nova, v. 3, n. 4, São Paulo, junho, 1987, 10 p.

FLAUZINA, A. L. P. Corpo Negro Caído no Chão: O Sistema Penal e o Projeto Genocida do Estado Brasileiro. 2006. Dissertação (Mestrado em Direito) - Universidade de Brasília, Faculdade de Direito, Brasília, 2006.

FOUCAULT, M. Vigiar e Punir. Rio de Janeiro: Forense Universitária, 2004.

FREIRE, A. C. C.; PONDÉ, M. P.; MENDONÇA, M. S. S. Saúde mental entre presidiários na cidade do Salvador, Bahia, Brasil. In: Maria Thereza Dantas Ávila Coelho e Milton Júlio de Carvalho Filho (Orgs.) Prisões numa abordagem interdisciplinar. Salvador: EDUFBA, 2012, pp 121-130.

LAROUZÉ, $B$ et al. Tuberculose nos presídios brasileiros: entre a responsabilização estatal e a dupla penalização dos detentos. Cad. Saúde Pública, 
v.31 ,n. 6, p 1-4, Rio de Janeiro, junho, 2015.

MBEMBE, A. Necropolítica. Arte \& Ensaios, revista do ppgav/eba/ufrj | n. 32 | dezembro 2016, p30.

MENEZES, R. P. O. Projeto de Implantação do Controle da Tuberculose nas Instituições Penais do Município de Salvador/Ba. Boletim de Pneumologia Sanitária, v. 10, n. 2, Rio de Janeiro, dez. 2002, p1-6.

MINAYO, M. C. S.; RIBEIRO, P. C. Deserdados sociais: condições de vida e saúde dos presos do estado do Rio de Janeiro. Editora FIOCRUZ, Rio de Janeiro, 2015.

ROCHA, A. P. da. O Estado e o Direito de Punir - A superlotação no Sistema Penitenciário Brasileiro. O caso do Distrito Federal. 200, 250, Dissertação (Mestrado de Ciências Políticas) -Universidade de Brasília, Brasília, 2006.

SALLA, F. As prisões em São Paulo: 1822-1940. São Paulo: Annablume/ Fapesp, 1999

SALLA, F. As rebeliões nas prisões: novos significados a partir da experiência brasileira. Sociologias, Porto Alegre, ano 8, no 16, jul/dez 2006, p. 274-307

SÁNCHEZ, A.; SIMAS, L.; DIUANA, V.; LAROUZE, B. COVID-19 nas prisões: um desafio impossível para a saúde pública? Cad. Saúde Pública, 36, maio, 2020, p 1-5.

SÁNCHEZ, A.; LAROUZÉ, B. Controle da tuberculose nas prisões, da pesquisa à ação: a experiência do Rio de Janeiro, Brasil. Ciênc. saúde coletiva, v. 21, n. 7, Rio de Janeiro, 2016. p.2071-2080

SINHORETTO, J.; SILVESTRE, G.; MELO, F. A. L. O encarceramento em massa em São Paulo. Tempo Social, v. 25, n. 1, São Paulo, dez, 2013, p 83-106.

SOUZA, C. M. C. de. A "espanhola" em Salvador - o cotidiano da cidade doente. Varia hist., Belo Horizonte, v. 25, n. 42, julho-dezembro, 2009, $25 p$.

SOUZA, L. K. Pesquisa com análise qualitativa de dados: conhecendo a Análise Temática. Arquivos Brasileiros de Psicologia, vol.71 no.2, Rio de Janeiro, maio-agosto,2019, p 1-17.

VALENÇA, M. S. et al. Tuberculose em presídios brasileiros: uma revisão integrativa da literatura. Ciênc. saúde coletiva, Rio de Janeiro, v. 21, n. 7, jul. 2016, p13-28. 